\title{
Harmonisation of the Turkish Electricity Transmission Grid Regulations in Line with ENTSO-E
}

\author{
Pascal Bertolini ${ }^{1}$, Mehmet Kara ${ }^{2}$
}

\begin{abstract}
The Turkish power system is now permanently operated in synchronous connection with the system of Continental Europe. A common set of rules is needed for operational monitoring and coordination of this highly integrated system, especially in the context of rapid penetration of renewable energy sources. Moreover, market regulations in Turkey shall need to facilitate cross-border trading with ENTSO-E members and prepare the Turkey's integration into the European wholesale electricity market. The alignment of Turkish connection requirements with those of Continental Europe is another step towards consistent operation by standardising the design of users' facilities in the whole interconnected system.

To meet these objectives, the Turkish power system regulations are in the process of being harmonised in order to be in line with ENTSO-E technical standards for the operation of the interconnected grid of Continental Europe (the Operation Handbook) and with nine draft EU network codes and regulations. TEIAS is carrying out this harmonisation of regulations as part of a project cofinanced by the European Union and the Republic of
\end{abstract}

\footnotetext{
${ }^{1}$ Team leader of the technical assistance to TEIAS RTE-International

Tour Initiale - 1, Terrasse Bellini - TSA 41000 - F-92919 La Défense Cedex (e-mail: pascal.bertolini@rte-france.com)

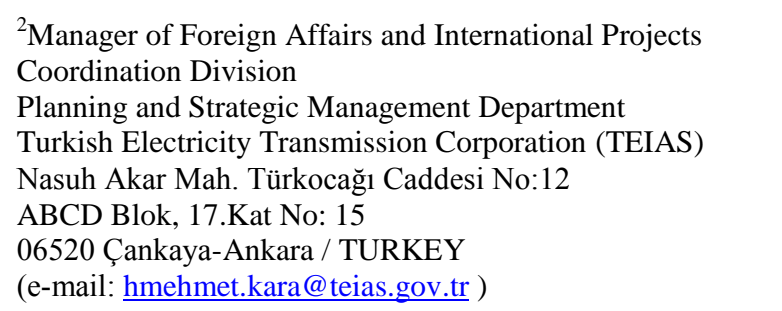

Turkey Service, with the assistance of a consortium led by RTE International. The project is now completed and the amended Turkish regulations will be published as soon as the corresponding EU network codes and regulations are enacted.

\section{Keywords}

Electricity, ENTSO-E, Network code, Transmission System Operator, Regulation, Turkey,

\section{Acknowledgement}

The project presented in this article is co-financed by the European Union and the Republic of Turkey as part of the EU National Programme for Turkey 2010 under the Instrument for Pre-Accession Assistance (project TR 2010/0315.01-01/001).

\section{Introduction}

This paper describes the process of harmonisation of the Turkish transmission grid code and other relevant Turkish regulations in order to be in line with ENTSO-E requirements. To meet this objective, a project cofinanced by the European Union and the Republic of Turkey provided technical assistance to TEIAS from March 2014 to April 2015. The paper mainly focuses on three key aspects of this technical assistance:

- the ENTSO-E requirements considered for the harmonisation (draft European network codes and Operation Handbook),

- the main activities carried out in order to achieve the harmonisation (drafting of the harmonised Turkish regulations, public consultation and training of TEIAS staff) and

- an overview of amendments and new concepts

This is an Open Access article distributed in accordance with the Creative Commons Attribution Non Commercial (CC-BY-NC-ND 4.0) license, which permits others to copy or share the article, provided original work is properly cited and that this is not done for commercial purposes. Users may not remix, transform, or build upon the material and may not distribute the modified material (http://creativecommons.org/licenses/by-nc/4.0/) 


\section{P. Bertolini, M. Kara \\ Harmonisation of the Turkish Electricity Transmission Grid Regulations in Line with ENTSO-E}

introduced into the Turkish regulations (for connecting new facilities, real-time operational security, capacity allocation on cross-border connections and balancing).

\section{Background and Objectives}

With the signature of the Long Term Agreement between TEIAS and ENTSO-E (15 April 2015), the Turkish power system is now permanently operated in connection with the system of Continental Europe. This is a major step for the integration of the Turkish system into the European electric system, opening the way to new opportunities to reinforce this integration both for market activities and flexibility of network operation.

Over the past four years, ENTSO-E has drafted a first set of nine European network codes and regulations. They are in the process of being approved by the European Commission (EC) before entering into force (Comitology). A first regulation (regulation on Capacity Allocation and Congestion Management) was published in the Official Journal of the European Union on July 2015 and entered into force on 14 August 2015. The network code on "Requirement for Generators" was adopted by EU member states in June 2015 and is on the way to getting final approval from the EU parliament and the EC. The other seven network codes and regulations in this first set are also expected to be adopted in 2015 according to EC views.

In this context, a project co-financed by the European Union and the Republic of Turkey was carried out between March 2014 and April 2015, with the aim of providing technical assistance to TEIAS for the harmonisation of the Turkish transmission code in line with ENTSO-E. This technical assistance was provided by a consortium, composed of RTE International (France), ELIA Grid International (Belgium) and FICHTNER (Germany), and led by RTE International.

This project achieved the harmonisation of Turkish power system regulations with the ENTSO-E requirements, aiming at setting rules for the integration of renewable and other types of facilities connected to the grid, adopting common rules for the operation of the interconnected grid of Continental Europe, fulfilling ENTSO-E requirements in the fields of power system operational security and quality of supply, and preparing the integration of the Turkish Electricity Market into the EU Internal Electricity Market.

Beyond this harmonisation of regulations, TEIAS staff were trained to work in this increasingly European integrated environment. To meet such an objective, the project included study tours and training activities.

The consortium also fulfilled a complementary objective, training TEIAS to conduct a public consultation using the best European practices in consultation techniques (workshops, written public consultation). The output of such a consultation is a key element in helping regulators understand the choices made in the code and explaining stakeholders' requests and constraints and the arbitrage made while drafting the code.

\section{ENTSO-E requirements considered for the harmonisation}

The Turkish Grid Code and the other relevant Turkish regulations have been updated in order to be in line with the draft European network codes and regulations on one hand and with ENTSO-E technical standards for the operation of the interconnected grid of Continental Europe (the Operation Handbook) on the other hand.

\subsection{The European network codes and regulations}

The European network codes and regulations are a set of rules drafted by ENTSO-E, with guidance from the Agency for the Cooperation of Energy Regulators (ACER), to facilitate the harmonisation, integration and efficiency of the European electricity market. Each network code is an integral part of the drive towards completion of the internal energy market, and achieving the European Union's 20-20-20 energy objectives of:

- A $20 \%$ reduction in EU greenhouse gas emissions from 1990 levels;

- Raising the share of EU energy consumption produced from renewable resources to $20 \%$;

- A $20 \%$ improvement in the EU's energy efficiency.

Representing European electricity transmission system operators, ENTSO-E was mandated by the European Commission (EC) to draft these rules for electricity, with sister association ENTSOG drafting the rules for gas. Under development since 2011, each code takes approximately 18 months to complete. Following ACER's recommendation, each code is submitted to the European Commission for approval through the Comitology process, to then be voted into EU law and implemented across Member States.

The network codes cover three key areas of the European electricity transmission sector:

- Grid connections: Clean low-carbon renewable electricity generation is on the rise, with wind capacity possibly meeting 
P. Bertolini, M. Kara
Harmonisation of the Turkish Electricity Transmission Grid Regulations in Line with ENTSO-E

$14 \%$ of European electricity consumption by 2030. However, these energy sources have different technical parameters from traditional fossil fuel sources and their large scale penetration will drastically change the way the transmission grids are operated. Therefore the grid connection rules need to be adapted to get this energy on the grid. Connection codes cover these challenges. They apply not only to generating units but also to demand facilities, transmission connected distribution systems and HVDC systems.

- Grid operations: The European electricity system is increasingly integrated, allowing better distribution of electricity resources across all Member States. While European electricity generators, operators and distributors have been working together for decades, a highly integrated pan-European electricity system means consistent operational monitoring and coordination across all the $27 \mathrm{EU}$ countries. Operational codes cover these challenges. They mainly cover two fields of activity, the process of outage scheduling of the elements of the interconnected network and the load frequency control.

- Cross-border electricity markets: Crossborder trading through the integration of the European wholesale electricity market helps ensure security of supply and optimum pricing for the different types of energy. Cross-border physical power flows are continuously increasing inside Europe but market integration is not yet complete. The market codes set down rules to harmonise cross-border power trading, creating an equal playing ground for all market participants, leading to more cost efficient electricity. They mainly cover rules for capacity calculation and congestion management in day-ahead and intraday, forward capacity allocation and rules for electricity balancing.

\subsection{The Operation Handbook}

The Operation Handbook $(\mathrm{OH})$ is a comprehensive collection of technical standards for the operation of the interconnected grid of Continental Europe. It is divided into 8 Policies:
- Load frequency Control and Performance

- Scheduling and Accounting

- Operation security

- Co-ordinated Operational planning

- Emergency Operations

- Communication Infrastructure

- Data exchanges

- Operational Training

\section{Main activities for achieving the harmonisation}

The technical assistance has been carried out through four main activities:

- Review of European and Turkish regulations and conducting of gap analyses,

- Drafting a first set of harmonised regulations,

- Public consultation,

- Study visits and training activities.

\subsection{Review of European and Turkish regulations and conducting of gap analyses}

This activity enabled a review of European and Turkish regulations, the working out of a gap analysis and the drafting of a first set of harmonised Turkish regulations which have been consulted in the following steps of the project.

The gap analysis was based on the comparison of the nine network codes drafted by ENTSO-E and the ENTSO-E technical standards for the operation of the interconnected grid of Continental Europe (the Operation Handbook) on one hand with ten distinct Turkish regulations and four other relevant Turkish documents (various agreements and rules) on the other hand. For legal issues, the Technical Assistance Team also considered more general laws for the Turkish electricity sector.

\subsection{Drafting a first set of harmonised regulations}

This first activity was completed at the beginning of December 2014 with the publication on the TEIAS website of the draft harmonised Turkish regulations and documents for public consultation (publication of 7 amended regulations and rules and 2 supporting documents).

\subsection{Public consultation}

The amendments proposed to be introduced into the Turkish regulations entail a major change in the 
functioning of the Turkish power system. About one thousand amendments are proposed to be introduced into Turkish regulations. This is the first reason for organising a consultation process on this revision.

Another reason for organising this public consultation is to meet the harmonisation objectives of the technical assistance mentioned above. Public Consultation is in fact mandatory in European regulation for developing network codes (Regulation (EC) 714-2009). European TSOs are also required to consult on a draft proposal before implementing measures pursuant to European network codes. This requirement is included in most of the network codes. As a result, full harmonisation with European regulation requires the introduction of a consultation process in Turkey.

Lastly, public consultation was very beneficial for stakeholders, TEIAS and the Turkish regulatory Authority (EMRA). The final regulations after public consultation were improved by including the views and proposals of all relevant parties. They will also be more robust in case of future disputes.

The consultation process was conducted by TEIAS in an open and transparent manner, involving all relevant market participants, and, in particular, the organisations representing all stakeholders. That consultation also involved national regulatory authorities and other national authorities, supply and generation undertakings, system users including customers and distribution system operators, including relevant industry associations, technical bodies and stakeholder platforms. The consultation process was mainly based on a written public consultation during which all relevant parties could send comments on the consulted draft regulations. Along with this written process, TEIAS organised two public workshops to present the amendments and help the relevant parties to make their comments.

\subsection{Study visits and training activities}

Finally, the technical assistance enabled TEIAS employees to be trained to work in an increasingly European-integrated environment. Six study tours of one week in Europe were organised for 12-15 people each and a theoretical training program was held in Ankara for about 30 engineers. The study tours were organised in Germany, Belgium, France and Switzerland, including visits to European coordination centres and national load dispatch centres and presentations on how the EU network code requirements are applied to ENTSO-E TSOs. The theoretical training session in Ankara allowed 28 trainees to be successfully certified.

\section{Overview of amendments and new concepts introduced into the Turkish regulations}

The gap analysis carried out by the technical assistance team led to about one thousand amendments being introduced into Turkish regulations in three main fields:

- Connection of new facilities

- Real-time operational security,

- Capacity allocation on cross-border connections and balancing.

\subsection{Amendments for connecting new facilities}

More than 500 amendments are proposed to be introduced into the Turkish regulations related to requirements for connecting new facilities. They apply to generators, demand facilities, transmission connected distribution networks and HVDC systems, as well as generators connected to distribution networks (wind turbines, domestic solar cells, etc.). Amendments on connection issues achieve the harmonisation of Turkish regulations with the three European draft network codes on "requirements for Generators", Demand connection" and "HVDC connections \& DC connected Power Park Modules".

It is recommended that these amendments are adopted into the Turkish regulations as soon as possible. They will be applicable to new facilities while the requirements of the existing Turkish regulation will still remain in force for existing facilities.

All ENTSO-E requirements for generation, demand and HVDC facilities are proposed to be introduced in the Turkish regulation except requirements for offshore power park modules (either AC or DC collected), and binding demand side response for demand facilities. These last requirements need further definition at European level before being implemented and it is preferable to postpone their introduction into Turkish regulation.

\subsection{Amendments for real time operational security}

About 300 amendments are proposed to be introduced into the Turkish regulations for real-time operational security. These requirements apply to TEIAS, DSOs and grid users. They achieve the main goal of keeping the European interconnected transmission system in a continuous and safe operation state. These amendments are aimed at the adoption of common rules for operating the European interconnected network. They mainly cover 
two fields of activity, the process of outage scheduling of the elements of the interconnected network and the load frequency control in the Continental Europe synchronous area to which the Turkish system is already interconnected. Amendments on operational security issues achieve the harmonisation of Turkish regulations with the three European draft network codes on "Operational Security", "Operational Planning and Scheduling" and "Load Frequency Control \& Reserve" and with the RGCE Operation Handbook.

\subsection{Capacity allocation on cross-border connections and balancing}

About 150 amendments are proposed to be introduced into the Turkish regulations for preparing the integration of the national Turkish electricity market and balancing activities into wider scale entities such as coupled markets or cross-border coordinated balancing areas. The adoption of common rules for capacity allocation (from forward markets to real time) and congestion management are essential steps for allowing such future integration of markets. Similarly, the adoption of common balancing products and of common rules for balancing will be an essential step for allowing the development of crossborder coordinated balancing areas. Amendments on market issues achieve the harmonisation of Turkish regulations with the three European draft network codes on "Capacity Calculation \& Congestion Management", "Forward Capacity Allocation" and "Electricity Balancing".

The harmonisation with ENTSO-E market codes will require great efforts from TEIAS in the coming years to comply with the very ambitious targets set in market codes for market integration in Europe. However, it is generally too soon to introduce mandatory requirements related to this target situation into the Turkish regulation. Most of the requirements either involve the implementation of measures taken in common with the other members of ENTSO-E (market coupling, flow based capacity allocation, financial transmission rights, cross-border balancing and balancing procurement) or need further definition at ENTSO-E level before being implemented. Few requirements are proposed to be introduced now, mainly for transparency purposes or when it allows Turkish internal processes and mechanisms to be prepared for joining such regional initiatives (firmness of long term transmission rights in case of force majeure, harmonisation of intraday market closing time, "use or sell it" principle for Physical Transmission rights...).

\section{Conclusions}

The project has been completed with the publication on the TEIAS website of the harmonised Turkish Transmission Code and other relevant Turkish regulations updated with the feedback of the public consultation:

- Electricity transmission grid regulation

- Electricity market distribution regulation

- Electricity market balancing and settlement regulation

- Electricity Market Ancillary Services Regulation

- Electricity Market Import and Export Regulation

- Principles and procedures on capacity allocation and secondary market for physical transmission rights in accordance with the electricity market export and import regulation

- Auction rules established by TEIAS and the neighbouring TSOs for the Allocation of Capacities on the Interconnection.

The amendments introduced into these regulations are aimed at setting rules for the integration of renewable and other types of facilities connected to the grid, adopting common rules for the operation of the interconnected grid of Continental Europe, fulfilling ENTSO-E requirements in the fields of power system operational security and quality of supply, and in the field of market issues, preparing the integration of the Turkish Electricity Market to the EU Internal Electricity Market.

This technical assistance also enabled TEIAS to be trained for conducting a public consultation using the best European practices in consultation techniques (workshops, written public consultation). The output of such a consultation is a key element in helping the regulator understand the choices made in the code and explaining the stakeholders' requests and constraints and the arbitrage made while drafting the code. This output is documented in three supporting documents drafted in addition to the harmonised regulations: an explanatory note, a draft legal guidance document and a consultation Report detailing the analysis of the comments received from the stakeholders.

Finally, the technical assistance enabled TEIAS employees to be trained to work in an increasingly European-integrated environment. Six study tours of one week in Europe were organised for 12-15 people each and a theoretical training program was held in Ankara for about 30 engineers.

These harmonised regulations and rules are not coming into force immediately in Turkey, mainly because the European network codes and regulations which were considered during the project had not yet been enacted and published at the date of completion of the technical assistance (April 2015). 
The process agreed for enacting Turkish regulations involves waiting first for the enactment and publication of the relevant network codes and regulations at the Official Journal of the European Union. After that, TEIAS will request the approval of the Turkish Regulatory Authority for Energy (EMRA) to introduce the corresponding amendments into the Turkish regulations. These actions will be performed after the completion of the project.

\section{The Authors}

Pascal BERTOLINI started working as researcher at EDF, Paris in 1982 after finalizing his education as engineer (Ecole Supérieure d'Electricité). Since 1999, he has been working at RTE, the French Transmission System Operator. He now works as projects director at RTE-International, a wholly-owned subsidiary of RTE, which promotes and markets throughout the world, the know-how and expertise of RTE.

He has an extensive experience in the field of access to the grid, ancillary services, grid codes and contractual agreements with grid users. In the last years, he worked at the department of RTE in charge of the access to the grid and had more particularly conducted the design and implementation of an equitable mechanism allowing RTE to divide the obligations of ancillary services between producers (for frequency and voltage control) and pay them an amount of about $€ 300 \mathrm{M}$ per year. He has also introduced an innovative approach to performance monitoring into the ancillary services agreements, allowing RTE to continuously monitor all the generating units contributing to frequency and voltage control (various papers in CIGRE and IEEE conferences).

$\mathrm{He}$ also actively worked in ENTSO-E as RTE member in the team in charge of drafting the EU network code on HVDC connections and as member of various working groups on frequency control and reserve dimensioning.

In 2014 and beginning of 2015, he was the team leader of a project in Turkey financed by $\mathrm{EU}$ for the "harmonization of the Turkish transmission code in line with ENTSO-E”.

Mehmet KARA started working in a private company after graduating from Selcuk University as electrical and electronics engineer. Since 1997, he has been working in Turkish Transmission system Operator, TEIAS (Turkish Electricity Transmission Co.”.

He works as manager of foreign affairs and international projects coordination division. Before this post, he worked in long term planning division and load dispatch departments of TEIAS. He was been actively participated "Complementary Studies for the Synchronisation of Turkish Power System with UCTE System" and "Rehabilitation of the Frequency Control Performance of Turkish Power System for Synchronous Operation with UCTE" projects which were financed by EU.

He has an extensive experience in simulation of electrical systems, steady state load flow analyses \& Dynamic analyses, short circuit \& optimum power flow analyses, primary frequency control reserve tests in power plants, PSS (Power System Stabilizer) tests in power plants. He has been involved in congestion management, cross-border electricity trade and capacity auctions in the last years.

He represents TEIAS in ENTSO-E Plenary. He also works in various working groups in MedTSO.

In 2014 and beginning of 2015, he was the project coordinator of "harmonization of the Turkish transmission code in line with ENTSO-E" which is financed by EU. 